\title{
Need of professionalism in geomatics profession for the development of sustainable system
}

\author{
Umesh Kumar $^{1}$ and Rabin K. Sharma ${ }^{2}$ \\ 1. Instructor, Land Management Training Centre \\ e-mail: Imtc@ntc.net.np \\ 2. Director General, Survey Department \\ e-mail: sharma19434@alumni.itc.nl
}

\section{Introduction}

Government of Nepal visualized for building new Nepal by development of sustainable system for good governance. The basic elements of good governance are: sustainable economic growth, incremental agricultural productivity, preservation of environment, reduction of poverty, easy access to proper education and health, etc. Accurate, reliable and operable spatial and attribute data are the fundamental input to address these issues. The data can be made available through the profession of Geomatics and professionals from this discipline are the one who create the data and this data set could be at the level of expectations for the user communities for the development of sustainable system when the professionals bear their professionalism. So it is felt that there is a need of professionalism in Geomatics profession for the development of sustainable system.

Development of professionalism for a professional from Geomatics profession is not an easy task. The professionals must have adequate education background and should affiliate with different institutions such as national and international organizations and its own working place for enhancing its capabilities and updating the knowledge necessary for the profession. Because, the government is responsible to uplift the entire society by facilitating social, economical and environmental issues which is depend upon the sustainable system of the government which in turn to be rely on the input data that are generated by the professionals from Geomatics profession. So they must feel high responsible for their job which is possible only when (s)he bears a good professionalism. This indicates that there is a relation between profession, professional and professionalism for development of sustainable system. This paper tries to identify the inter-relation between these elements by analyzing the related components

\section{Definition of a Surveyor}

Surveyor is one of the key persons of a country for the national development. It is a well known fact that every activities of national development need data and information related to land, sea and the Universe. The Surveyors are the one who collect, process and present data which are based on the actual field work or the information gathered through remotely sensed techniques. So as per the Land (Survey \& Measurement) Regulations 2058, the works of surveyor are defined as follows:

- To conduct cadastral mapping which includes preparation of land records related to land owner and the tenant, preparation of cadastral plan, finding out area of the parcel, classification of land, preparation of field book.

- To operate aerial photography mission

- To establish control points

- To prepare topographical maps of various scales

Government of Nepal has made a provision to issue license to a qualified surveyor as mentioned in the article 11e of Land (Survey and Measurement) Act 2019 (Eight Amendment 2056). In this context "Licentiate Surveyor" is defined as surveyor who have obtained license under the Article 26 of Land (Survey and Measurement) Regulations 2058 and the license should be considered as a letter of permission for conducting survey and mapping in accordance with this Article.

International Federation of Surveyors (FIG) is a well known and recognized international organization for the surveyors and the definition of surveyor laid out by this organization is accepted globally and it defines as: 
"A Surveyor is a professional person with the academic qualifications and technical experiences to practice the science of measurement, to assemble and assess land and geographic related information; to use that information for the purpose of planning and implementing the efficient administration of the land, the sea and structures thereon; and to investigate the advancement and development of such practices."

So each individual surveyor must confine her/his responsibilities and duties within the limit set by the local and global definition of Surveyors for establishing her/his profession.

\section{Need of Professionalism}

Geomatics profession has direct link with the property mapping of each individual holding even a piece of land as well as with the activities related to national development such as land development, hydro power projects, road construction projects, irrigation projects, atlas preparation, etcetera. Because, all of these projects need accurate, reliable, standard and up-to-date spatial as well as attribute data for planning, designing and implementation. Establishment of such data needs to design a system for acquiring, processing and presenting the data. Human resources involved in this entire system belong to the Geomatics profession and they should possess the characteristics related to professionalism which are dedicated, qualified, competent and honest for its profession. So it is obvious that for development of sustainable system, Geomatics professionals must have professionalism otherwise there could be a high chance for the failure of the project. On the other hand, sustainable system is required for the government to exercise the power in managing social, economic and natural resources for attaining good governance. It can be achievable only when it fulfills the norms identified in the UN Habitat Global Campaign on Urban Governance; adopted from FAO 2007. They are as follows:

- Sustainable and locally responsible

- Legitimate and equitable

- Efficient, effective and competent

- Transparent, accountable and predictable

- Participatory and providing security and stability

- Dedicated and integrity

So, the professionals should work hard to develop sustainable system and to support for establishing good governance, however, professionals bearing professionalism could stand to develop sustainable system because such professionals could establish good relation between political and bureaucratic system and without their understanding no project can succeed to achieve goals of the project.

\section{Basic Entities of Professionalism}

When an individual received a certain degree of training or studied some level of academic course in the field of Surveys or Geomatics, (s)he is qualified to become a surveyor. But to be recognize as a professional surveyor, (s)he must possess some basic entities of the professional and they are specified as academic qualification and/or training and the elements of professionalism.

\subsection{Education of Surveyor}

In Nepalese context, an individual is named as a surveyor when (s)he has acquired one of the following training courses or academic degree:

a) Training course

i. Basic Surveyor course of 12 months duration

ii. Junior Surveyor course of 12 months duration

iii. Senior Surveyor course of at least 12 months duration

iv. Survey Graduates or equivalent course from a recognized institution

\subsection{Elements of Professionalism}

The elements of Survey Professionalism are as follows:

- Role of an Employee: Most of the surveyors will attach with either public or private organization as an employee. So (s)he must play the role to achieve the goal of the organization as defined in the works, duties of responsibilities of her/his job description.

- Role of Professional Practitioner: Surveyor can practice his profession as a professional practitioner.

- Role of a Member of Professional Organization: It is obvious that professional organizations and the profession are inter-linked terms because the professional organization could evaluate as a good organization only when the professionals of the organization are active and bears good professionalism. So to maintain the sustainability of this inter-relationship the surveyors must affiliate with the professional organization and should contribute her/his services in the activities to foster the organization as well as professionalism of the sector. 


\section{Organization}

Organization also guides professionals for achieving professionalism in their profession. The organization could be educational institution, national professional organization, international organization and the working organization. Each influences the professionals in different ways for developing their professionalism.

\subsection{Educational Institution}

Educational institutions for the production of Geomatics professionals are training and academic institutions. At present, the following private training institutions impart training course for basic surveyors under the approval from Council for Technical, Educational and Vocational Training (CTEVT):

1. School of Geomatics, Kathmandu

2. S.K. Institute of Technology, Mahendranagar

3. Kailali Polytechnical Institute, Dhangadhi

4. Narayani Training Centre, Bharatpur

5. Baglamukhi Technical Institute, Itahari

6. Nepal Technical Institute, Janakpur

Furthermore, School of Geomatics also conducts Diploma in Surveying. One more private institution: Geomatics Information Technology, Kathmandu; affiliated with Purbanchal University conducts Graduate course in Geomatics and Land Management Training Centre, Dhulikhel: the only Government Institution of Nepal for Geomatics profession imparts training for Basic, Junior and Senior Surveyor courses and also conducts Bachelor of Engineering in Geomatics Engineering in collaboration with Kathmandu University. Educational institutions have greater responsibilities to produce good quality professionals and they are:

- Designing standard curriculum for the courses

- Selecting enthusiastic students for learning

- Managing motivated resource persons for teaching

- Organizing effective class routines for the course

- Ensuring adequate infrastructure for teaching and for extra curricular activities

- Ensuring sufficient financial resources

- Attempting to establish good relation between the class and the teacher for maintaining the spirit of teaching and learning

\subsection{National Professional Organization}

Geomatics encompasses several disciplines and each discipline associated with its own organizations and furthermore the group of professionals of a particular discipline established their own professional organization. The common objectives of these professional organizations are mainly to secure and promote the profession, to facilitate regular dissemination of new ideas and technology, and to play an advisory role in formulating policies and programmes in their corresponding domain. Some of the professional organizations involved for developing professionalism in the field of Geomatics are as follows:

1. Nepal Geographical Society (NGS)

2. Nepal Engineering Association (NEA)

3. Nepal Geological Society (NGS)

4. Nepal Surveyor's Association (NESA)

5. Nepal Geographical Information System Society (NEGISS)

6. Nepal Remote Sensing and Photogrammetric Society (NRSPS)

7. Nepal Institution of Chartered Surveyors (NICS)

So the professionals should join at least one related professional organization as a member and should actively involve in the activities for achieving the goals of the organization and consequently, helps in development of professionalism.

\subsection{International Organization}

In Agenda 21 of the Earth Summit 1992 of Rio de Janeiro, it states that "No nation can achieve sustainable development of its own, so global partnership is being sought for the cause". So guided by this philosophy, Government of Nepal supported Survey Department of Nepal for joining the International Organizations and for participating the events of those institutions. The main objectives are to give exposure of the Department in international forum, to update knowledge on recent developments in the field of Geomatics, to exchange views and experiences for solving the common technical problems with the experts from different parts of the world, to cooperate mutually for the development of technological advancement etc. The following are the organizations where Survey Department has acquired membership:

1. SAARC Networking Arrangement on Cartography (SNAC)

2. Permanent Committee on GIS Infrastructure for Asia and the Pacific (PCGIAP) 
3. International Steering Committee for Global Mapping (ISCGM)

4. Asian Association on Remote Sensing (AARS)

5. Asia Pacific Regional Space Agency Forum (APRSAF)

6. Group on Earth Observations (GEO)

7. International Federation of Surveyors (FIG)

8. Global Spatial Development Infrastructure Association (GSDIA)

9. Sentinel Asia Joint Project Team (SA JPT)

Land Management Training Centre (LMTC) also started foot stepping the same principle of Survey Department by joining the international organizations to enhance its training programmes for producing better professionals in the field of Geomatics. So far, LMTC received membership of FIG in 2006 as Educational Member and applied for the membership of Sentinel Asia Joint Project Team in 2009.

Professionals are advised to involve or participate in the activities of such international organizations because one of their objectives is to emphasize on strengthening professional institutions promoting professional development; and encouraging professionals to acquire new skills and techniques. These objectives are set so that the professionals are properly equipped to meet the needs of society and the environment for facilitating economy, social and environmental sustainability.

\subsection{Working Organization}

A professional, in general, will attach to one organization: public or private, where her/his role will be to fulfill partially the objectives of the organization and in return (s)he will get her/his salary. At the same time (s)he will get opportunities to enhance her/his capabilities through sharing the issues, problems, solutions and technologies with the colleagues, clients, experts, etc. and also the same can be achieved by participating national and international meetings, seminars, conferences, etc. This will lead the professionals for development of its professionalism.

\section{Profession, Professional and Professionalism}

Inter-relation between profession, professional and professionalism can be illustrated with the diagram below:

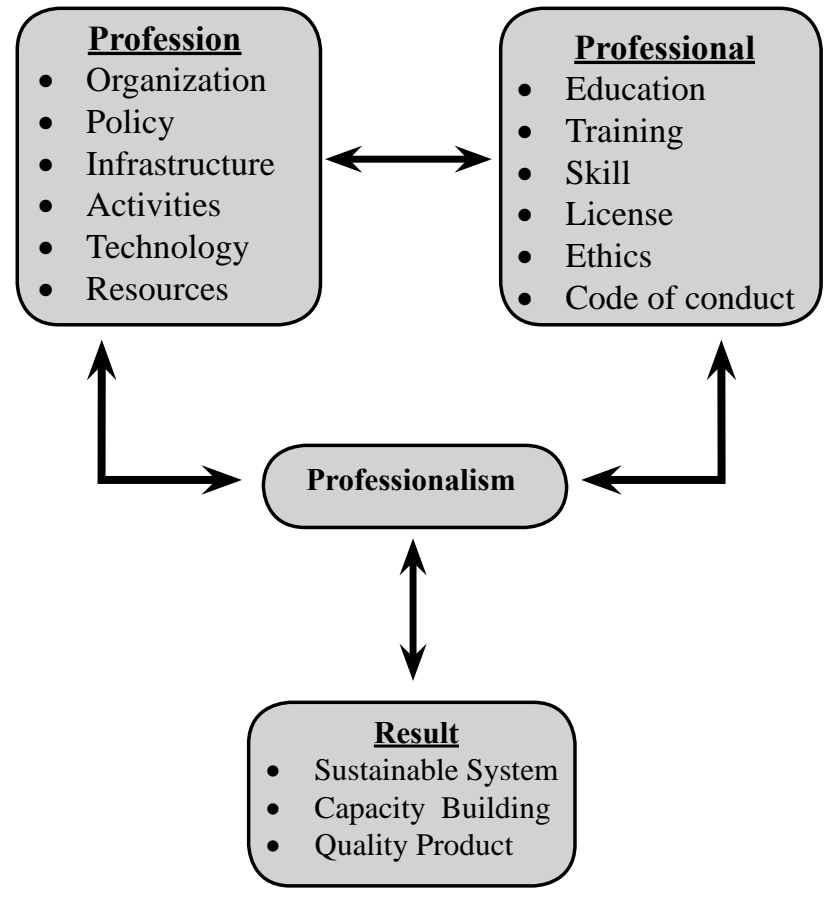

Figure: Inter-relation between Profession, Professional \& Professionalism

Profession in an organization is always guided by governmental policies and activities supported by infrastructure, human and financial resources and technology in a particular field. A professional is distinguished by certain characteristics having a specified education and training, and having command and skill on a particular field, and enforcing them for following ethics and code of conduct of the profession resulting to development of professionalism. The end results in the environment of profession with such professional will be quality products, capacity building and sustainable system.

\section{Conclusion}

It is clear that there is a strong relation between profession, professional and professionalism. Geomatics professional must have specified qualification and/or training. S(he) could get a survey license issued by the related organization. Finally, (s)he must obey the ethics and code of conduct specified by the related organization. Some of the ways to develop her/his professionalism are to practice in a related organization, involve in professional organization and participate in the event of national and international organizations related to Geomatics profession. Such professionals could develop sustainable system and hence it is felt that professionalism is necessary in Geomatics profession for the development of sustainable system for 
achieving good governance in the country.

\section{Reference}

1. Buddhi Narayan Shrestha; Licentiate Surveyor System in Nepal; Nepalese Journal on Geoinformatics, Number 7; 2008

2. Buddhi Narayan Shrestha; Need of Licensing in Surveying Profession; Nepalese Journal on Geoinformatics, Number 1; 2002

3. Earth Summit : Agenda 21; The United Nations Programme of Action from Rio; Rio de Janerio, Brazil; 3-14 June 1992

4. Land (Survey and Measurement) Act, 2056

5. Land (Survey and Measurement) Regulations 2058

6. Nab Raj Subedi; Surveying Profession and Professionalism; Nepalese Journal on
Geoinformatics, Number 6; 2007

7. Rabin K. Sharma; Profession and Professional Organizations in Nepalese Context; paper presented in XXI th ISPRS Congress 2008, Beijing China; July 3-11, 2008

8. Rabin K. Sharma; Professional Organizations of Geoinformatics in Nepal; Nepalese Journal on Geoinformatics, Number 7; 2008

9. Rabin K. Sharma; Survey Department in the Forum of International Activities: an Overview; Nepalese Journal on Geoinformatics, Number 3; 2004

10. www.fig.net 